\title{
Determining the required underground grout pack production profile for narrow tabular mining operations
}

\author{
Bernardt Van Der Spuy \\ Paterson and Cooke Consulting Engineers (Pty) Ltd, South Africa
}

\begin{abstract}
SUMMARY: South African gold and platinum mines commonly utilise narrow tabular mining for ore extraction. The removal of the ore body leaves open voids with stoping widths that can exceed $2 \mathrm{~m}$ in some mines. Props and cementitious grout packs are used extensively as stope support systems to stabilize the rock mass of the voids and to reduce the risks associated with rockfalls and rockbursts. The construction of grout packs for support follows the stope face advance and mining production is inter alia dependant on the production profile of the grout packs. The grout pack production system of a mine generally consists of a surface mixing plant and a reticulation system to the underground workings. A cementitious grout slurry is prepared at the mixing plant and is pumped to the underground stopes for filling of grout packs positioned between the hanging wall and footwall. Construction of grout packs in stopes is labour intensive and requires planning to ensure that the grout pack production profile meets the mining production profile. To determine the planned monthly grout volumes of a mining operation a variety of parameters need to be considered. These parameters should be accurately estimated at the start of a production month and are based inter alia on historical data and the mining plan of the operation. This paper presents a method to assist mining staff in estimating the required grout pack production profile, determining the required capacity of grout plants and reconciliation of the actual and planned grout pack production profile for a production month.
\end{abstract}

Keywords: backfill, mining, grout, optimisation, cemented hydraulic fill

\section{INTRODUCTION}

South African gold and platinum mines commonly utilise narrow tabular mining for ore extraction. The removal of the ore body leaves open voids with stoping widths of some mines in excess of $2 \mathrm{~m}$. Props and cementitious grout packs are used extensively as stope support systems to stabilize the rock mass of the voids and to reduce the risks associated with rockfalls and rockbursts (Daehnke, van Zyl \& Roberts, 2001).

The construction of grout packs for support follows the panel face advance and mining production is inter alia dependant on the production profile of the grout packs. Grout plants utilized in the South African mines generally consist of a batch mixing system with a continuous feed to underground operations.

In order to estimate the required grout plant/s production capacity for a mining operation a variety of parameters need to be considered. These parameters should be accurately estimated at the start of a production month and are based inter alia on historical data and the mining plan of the operation. 
The actual grout plant/s production capacity of a mining operation is determined by the possible grout flow rate that can be delivered to the underground operation. If the required volumes exceed the grout plant production capacity, the grout pack production profile will not be able to satisfy mining requirements. This paper presents a methodology to determine the required and actual plant/s production capacity in order to identify possible bottlenecks of the system and provides possible solutions to increase the capacity of the grout system.

\section{GROUT PACK FILL VOLUMES}

The pack types used to support the hanging wall depend on a variety of factors including the required in situ load bearing characteristics of the packs to support the hanging wall, in-stope space constraints and the stope standard.

Packs can have a square (see Figure 1) or circular (see Figure 2) plan area. Generally, square packs contain a centrally mounted wooden support pole while circular packs are reinforced and confined by placing the pack in a steel cage with support poles before filling and pressurizing the pack.

The grout volume required to fill a pack is determined by the volume of the bag used to contain the grout during filling. After the first fill of the pack is complete it is pressurized (commonly referred to as "stressing") by adding additional material to ensure a bond is created between the hanging and foot wall of the stope. This pressurization of the pack causes an increase in filling volume as the pack bulges, material consolidates and water seeps through the bag material.

\subsection{Theoretical fill volume (non-pressurized pack/non-stressed pack)}

A non-stressed, theoretical fill volume of a pack can be determined based on the pack plan area and the stoping width of a panel. This is the volume of the bag used to contain the grout material during filling. Panels mined in South African tabular mines generally have stoping widths of between $1.0 \mathrm{~m}$ and $1.8 \mathrm{~m}$. However, the development of gulleys and raises around

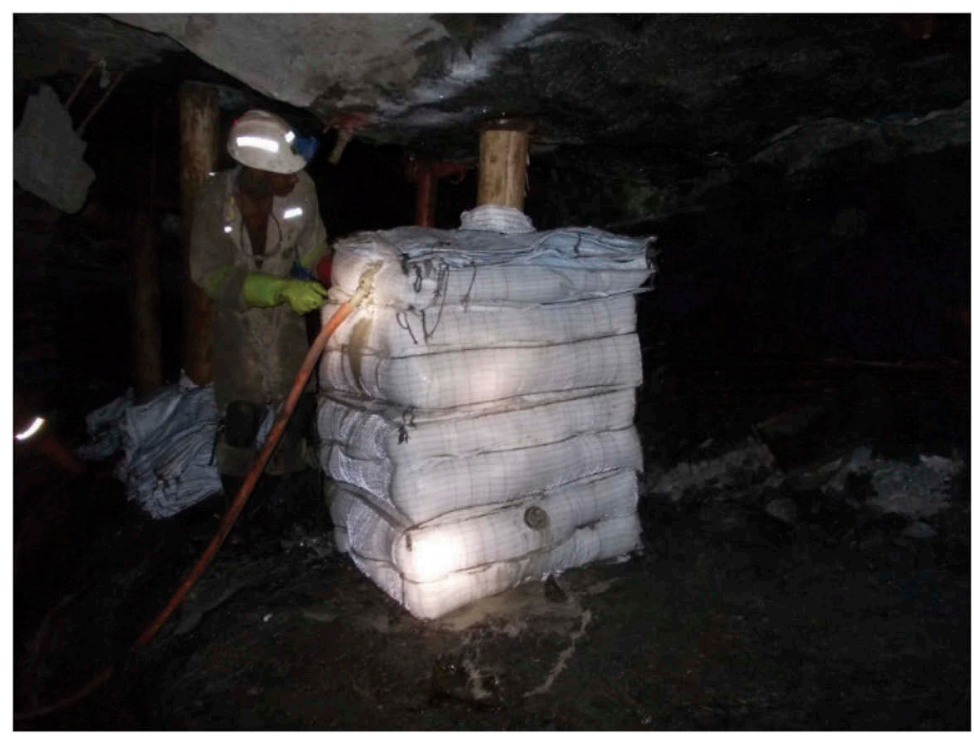

Figure 1. Square grout pack.

Source: own study 


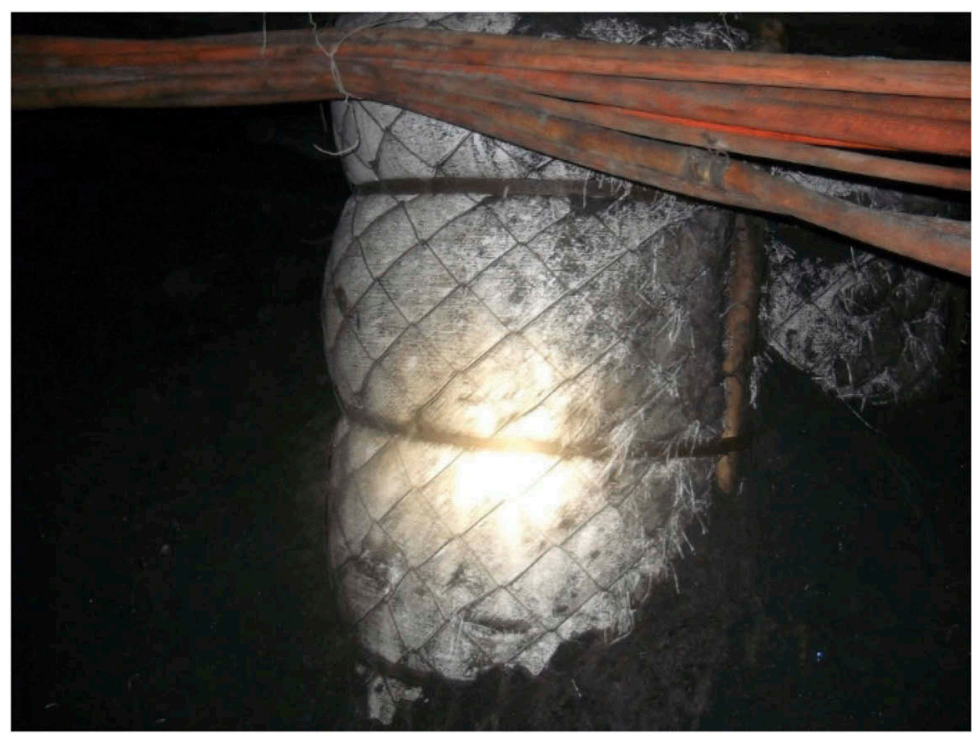

Figure 2. Circular grout pack with steel reinforced cage.

Source: own study

panels may require the installation of ledging packs on the panel edges which can have stoping widths exceeding $2 \mathrm{~m}$. The theoretical fill volume of a circular pack is determined as follows:

$$
V_{n s-r}=\frac{\pi \times D^{2}}{4} \times H
$$

where:

$\mathrm{V}_{\mathrm{ns}-\mathrm{r}}=$ non-stressed fill volume of round pack $\left(\mathrm{m}^{3}\right)$

$\mathrm{D}=$ outside diameter of pack $(\mathrm{m})$

$\mathrm{H}=$ stoping width $(\mathrm{m})$

The theoretical fill volume of a square pack is determined as follows:

$$
V_{n s-s}=\left(L^{2}-\left(\frac{\pi \times d^{2}}{4}\right)\right) \times H
$$

where:

$\mathrm{V}_{\mathrm{ns}-\mathrm{s}}=$ non-stressed fill volume of square pack $\left(\mathrm{m}^{3}\right)$

$\mathrm{L}=$ plan width of pack $(\mathrm{m})$

$\mathrm{d}=$ outside diameter of wooden pole $(\mathrm{m})$

$\mathrm{H}=$ stoping width $(\mathrm{m})$

\subsection{Theoretical fill volume (pressurized pack/stressed pack)}

The theoretical, pressurized/stressed fill volume of a pack is dependent on the following factors:

- Theoretical fill volume (Non-pressurized pack).

- Bulging of the pack during filling and pressurization.

- Seepage and consolidation of the grout material during filling and stressing. 


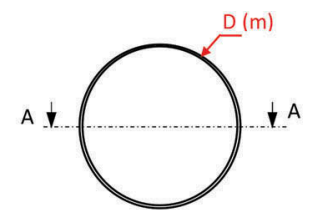

CIRCULAR GROUT PACK PLAN VIEW

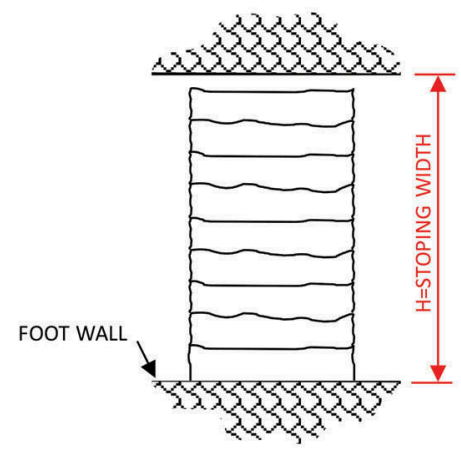

GROUT PACK SECTIONAL VIEW ON A-A

Figure 3. Theoretical fill volume - unpressurized circular grout pack with steel reinforced cage. Source: own study

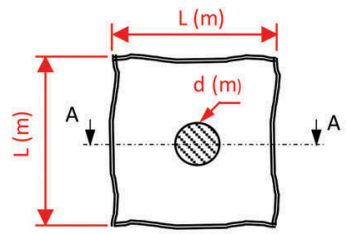

SQUARE GROUT PACK PLAN VIEW

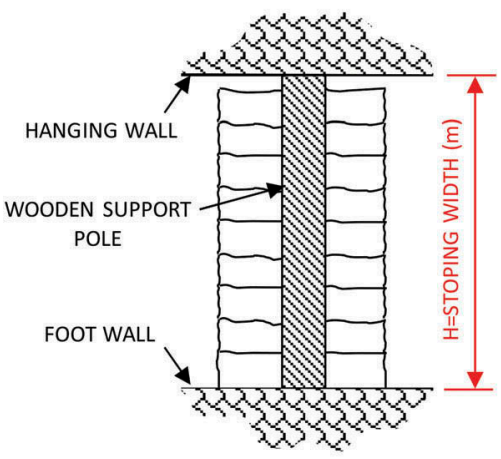

GROUT PACK SECTIONAL VIEW ON A-A

Figure 4. Theoretical fill volume - unpressurized square grout pack with wooden support pole. Source: own study 
The theoretical fill volume of a stressed pack is calculated as follows:

$$
V_{s}=V_{n s}+V_{b}+V_{s c}
$$

where:

$\mathrm{V}_{\mathrm{s}}=$ stressed fill volume of round or square pack $\left(\mathrm{m}^{3}\right)$

$\mathrm{V}_{\mathrm{ns}}=$ non-pressurized fill volume of round or square pack $\left(\mathrm{m}^{3}\right)-$ Refer to Section 2

$\mathrm{V}_{\mathrm{b}}=$ additional fill volume due to bulging $\left(\mathrm{m}^{3}\right)$

$\mathrm{V}_{\mathrm{sc}}=$ additional fill volume due to seepage from pack and consolidation of grout material $\left(\mathrm{m}^{3}\right)$

\subsubsection{Additional fill volume due to bulging $\left(V_{b}\right)$}

During pack filling, the grout material introduced into the grout pack causes an internal pressure to be applied on the pack wall segments. This internal pressure causes the woven pack material to stretch, resulting in a "bulging" effect and the whole pack experiences an increase in filling volume.

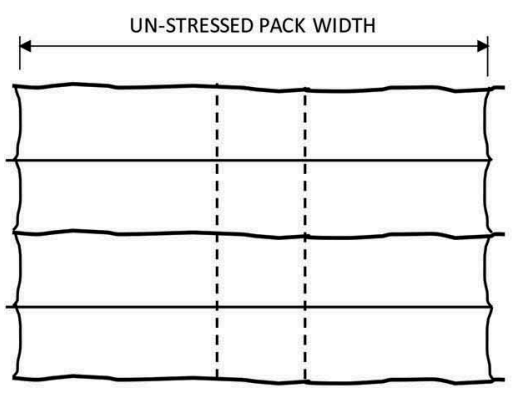

UN-STRESSED PACK

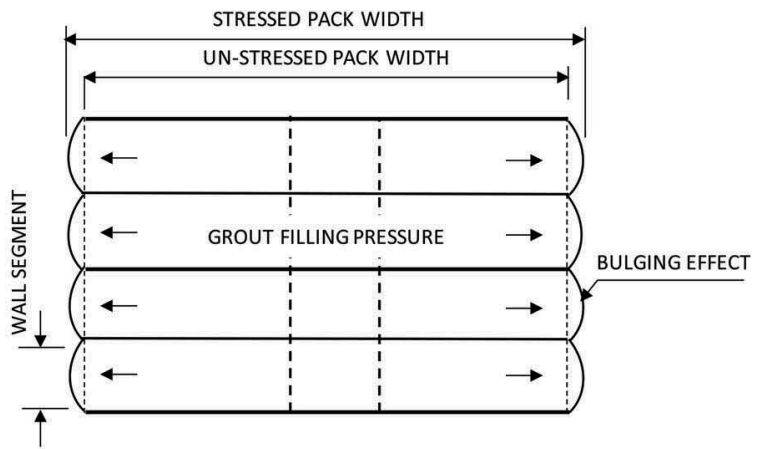

STRESSED PACK

Figure 5. "Bulging" effect on a single square bag during pack filling and stressing.

Source: own study

\subsubsection{Additional fill volume due to seepage from pack and consolidation of material $\left(V_{s c}\right)$}

Consolidation is a time-related process of dewatering the grout and increasing the density by seepage of interstitial water from voids between particles. As grout material is introduced into packs, the internal pressure induced causes water and fine particles in the grout mixture to seep through the woven grout pack.

The lost water and fines causes the consolidated density of the grout material in the packs to be higher than the pumped grout mixture density which in turn causes an increase in the pumping volume required to fill each pack.

The consolidation and seepage effect of the grout material is based on the mass concentration of grout material being introduced into the pack as well as the maximum bed packing concentration of the material. Material property test work is required to accurately calculate the increased grout volume required due this effect.

\section{STOPE STANDARD}

When constructing in-stope supports for the hanging wall, grout packs are spaced at fixed intervals to limit spans and provide the hanging wall support required to ensure 
a safe working environment for underground operations. The mining operation will generally have a stope standard (or distribution profile) to dictate the spacing of packs. The stope standard is generally determined by the mining operation's rock engineers and is dependent on the grout pack sizes, mining method employed, required accessibility for effective sweeping of panels and the ground conditions. As mining reaches deeper levels and ground conditions deteriorate, additional stope standards may be adopted.

Figure 6 presents a typical stope standard to be used by grout pack preparation crews for a breast mining operation. Crews will distribute the empty bags and relevant reinforcement at the specified intervals before pack filling commences.

In order to provide access space between the last row of packs and the mining face for mucking and crew access while still providing sufficient support for the hanging wall, the stoping standard requires a maximum first pillar row spacing of ' $\mathrm{e}$ ' $\mathrm{m}$ from the mining face. Ground conditions require in-stope packs to be spaced 'b' $\mathrm{m}$ apart on strike and 'a' $\mathrm{m}$ apart on dip.

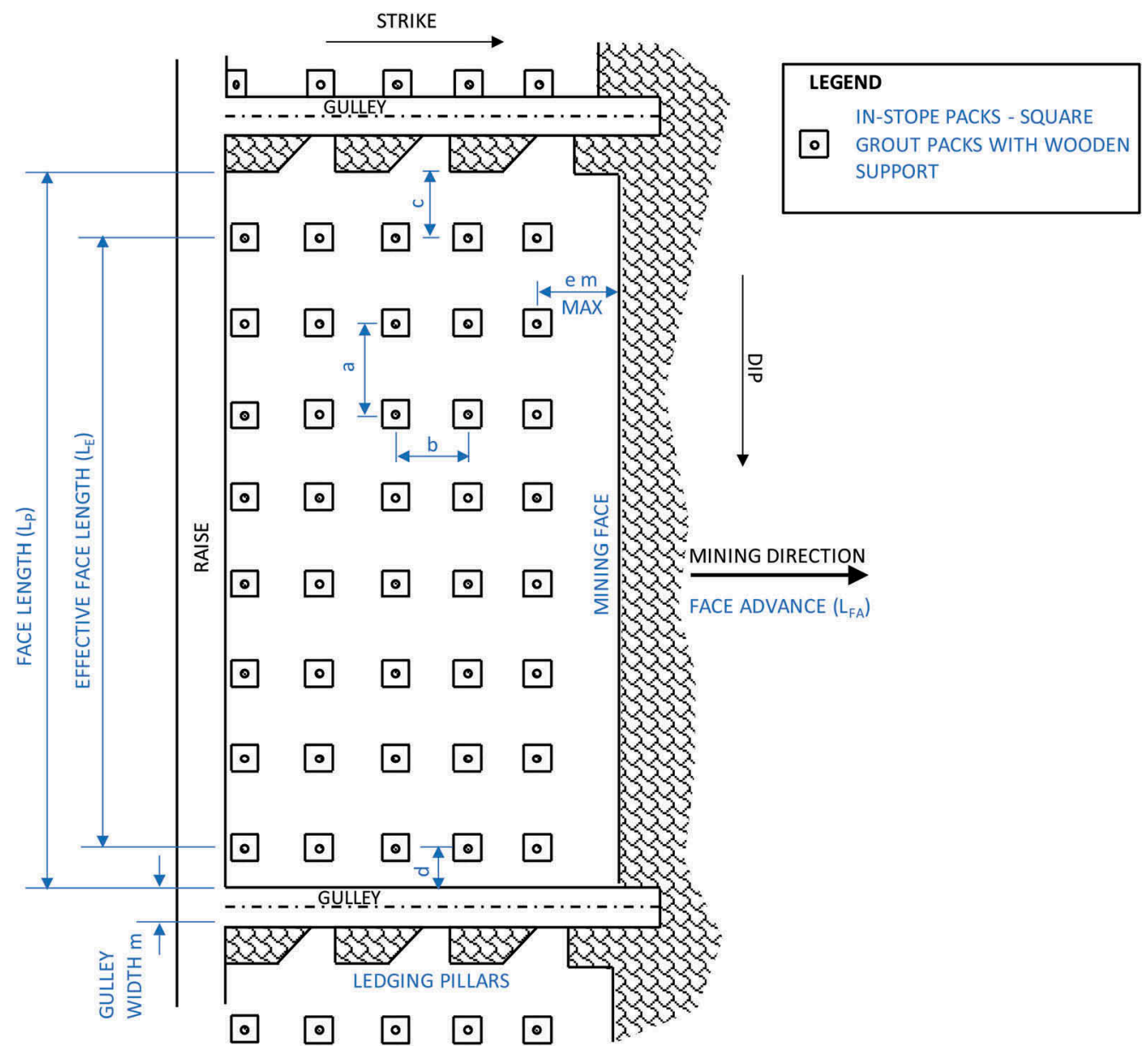

Figure 6. Typical stope standard used for pack construction in breast mining operation.

Source: own study 


\section{TOTAL VOLUME OF GROUT REQUIRED PER MONTH}

The total volume of grout required per month is based on various mine production parameters presented in the following section.

\subsection{Mine production parameters}

\subsubsection{Total stoping area to be mined for month $\left(A_{T}\right)$}

The total planned underground stoping area to be mined per month for the mine is projected at the start of a production month and is determined by the mining plan. Typically expressed in $\mathrm{m}^{2} /$ month.

\subsubsection{Average panel face length $\left(L_{P}\right)$}

The panel face lengths of underground panels are measured by surveying at the end of a production month. A planned, average panel face length can be estimated at the start of a production month based on historical surveyed data. Typically expressed in metres.

\subsubsection{Average stoping face advance $\left(L_{F A}\right)$}

The face advance of a mine is dependent on a variety of factors including the blasting schedule, stoping method and production efficiency of the mine. A planned, average stoping face advance can be estimated at the start of a production month based on historical data and the mining plan. Typically expressed in metres/month.

\subsubsection{Average stoping mining area per panel per month $\left(A_{P}\right)$}

An average planned mined area per panel/month is based on the planned, average stoping face advance as well as the planned, average panel face length:

$$
A_{P}=L_{P} \times L_{F A}
$$

where:

$A_{P}=$ average stoping mining area per panel per month $\left(\mathrm{m}^{2} / \mathrm{month}\right)$

$\mathrm{L}_{\mathrm{P}}=$ average panel face length $(\mathrm{m})$

$\mathrm{L}_{\mathrm{FA}}=$ average stoping face advance $(\mathrm{m} / \mathrm{month})$

\subsubsection{Number of panels mined per month $\left(N_{P}\right)$}

The planned number of panels to be mined per month is based on the planned, total stoping area to be mined for month and the calculated average mining area per panel/month:

$$
N_{P}=\frac{A_{T}}{A_{P}}
$$

where:

$\mathrm{N}_{\mathrm{P}}=$ number of panels mined per month

$\mathrm{A}_{\mathrm{T}}=$ total stoping area to be mined for month $\left(\mathrm{m}^{2} / \mathrm{month}\right)$

$A_{P}=$ average stoping mining area per panel $/$ month $\left(\mathrm{m}^{2} /\right.$ month $)$

\subsection{Total volume of grout required to satisfy planned mining parameters}

The mine production parameters (discussed in section 4.1) and the stope standard (discussed in section 3) are used to determine the required number of grout packs for the month. The required number of grout packs are subsequently used in conjunction with the grout pack fill volumes (discussed in section 2) to estimate the total volume of grout required for the production month. 


\subsubsection{Required number of grout packs for month $\left(N_{G P-T O T}\right)$}

The required pack spacing on the stope standard is used in conjunction with the number of panels mined per month $\left(\mathrm{N}_{\mathrm{P}}\right)$ to determine the planned number of grout packs to be filled per month.

The number of packs required on dip is determined by dividing the effective face length by the pack spacing on dip:

$$
N_{G P-D I P}=\frac{L_{E}}{a}+1
$$

where:

$\mathrm{N}_{\text {GP-DIP }}=$ number of packs required per panel on dip

$\mathrm{L}_{\mathrm{E}}=$ effective face length $(\mathrm{m})$

$\mathrm{a}=$ pack spacing on $\operatorname{dip}(\mathrm{m})$

The effective face length can be described as the total length between the first pack on dip and the last pack on dip. The effective face length is calculated from the average panel face length $\left(\mathrm{L}_{\mathrm{P}}\right)$ and the stope standard. The effective face length for the stope standard presented is calculated as follows:

$$
L_{E}=L_{P}-c-d
$$

where:

$\mathrm{L}_{\mathrm{E}}=$ effective face length $(\mathrm{m})$

$\mathrm{c}=$ first pack spacing from ledging pillar in panel $(\mathrm{m})$

$\mathrm{d}=$ last pack spacing from gulley edge $(\mathrm{m})$

The number of packs rows required on strike is determined from the average stoping face advance for the month $\left(\mathrm{L}_{\mathrm{FA}}\right)$ and the pack spacing on strike as determined by the stope standard:

$$
N_{G P-S T R I K E}=\frac{L_{F A}}{b}
$$

where:

$\mathrm{N}_{\text {GP-STRIKE }}=$ number of packs required per panel on strike

$\mathrm{L}_{\mathrm{FA}}=$ average stoping face advance $(\mathrm{m} / \mathrm{month})$

$\mathrm{b}=$ pack spacing on strike $(\mathrm{m})$

The number of required packs per panel is then determined as follows:

$$
N_{G P-P A N E L}=N_{G P-D I P} \times N_{G P-S T R I K E}
$$

where:

$\mathrm{N}_{\text {GP-PANEL }}=$ number of packs required per panel

$\mathrm{N}_{\text {GP-STRIKE }}=$ number of packs required per panel on strike

$\mathrm{N}_{\text {GP-DIP }}=$ number of packs required per panel on dip

Finally, the total number of required grout packs for the month is determined from the number of panels mined for the month:

$$
N_{G P-T O T}=N_{G P-P A N E L} \times N_{P}
$$

where:

$\mathrm{N}_{\text {GP-TOT }}=$ required number of packs for month

$\mathrm{N}_{\text {GP-PANEL }}=$ number of packs required per panel

$\mathrm{N}_{\mathrm{P}}=$ number of panels mined per month 


\subsubsection{Total volume of grout required for month $\left(V_{G}\right)$}

The planned, total volume of grout required per month is determined from the number of required packs for the month and the theoretical pressurized pack volume discussed in Section 2.

$$
V_{G}=N_{G P-T O T A L} \times V_{S}
$$

where:

$\mathrm{V}_{\mathrm{G}}=$ total volume of grout required for month

$\mathrm{N}_{\mathrm{GP}-\mathrm{TOT}}=$ required number of grout packs for month

$\mathrm{Vs}=$ pressurized volume of round or square pack $\left(\mathrm{m}^{3}\right)$

\section{REQUIRED SURFACE GROUT PLANT OUTPUT CAPACITY}

After the total volume of grout required for month is determined it can be related back to a required hourly grout flow rate to satisfy the planned mine production parameters. The flow rate is dependent on the possible daily crew production and the grout plant utilisation as discussed in the following sections.

\subsection{Possible daily crew production}

A production day on a South African platinum mining operation can typically be divided into three shifts:

$-1 \times 8$ hour blasting and cleaning shift

- 2 x 8 hour grout filling shifts including preparatory work such as drill, sweep, stope support, services installation etc.

\subsubsection{Blasting and cleaning shifts}

Only blasting crews are present in stopes to prepare panels for blasting during the first part of the shift. After blasting is completed, panel cleaning crews muck blasted ore into gulleys and raises for transportation to surface. During the blasting and cleaning shift no pack filling can be done as the safety of filling crews are of concern.

\subsubsection{Grout filling shifts}

During the remaining two production shifts in the mining operation, packs are constructed and filled in panels. Panels that will be mined in the following blasting and cleaning shift take preference to satisfy the required mining production profile of the mine. Backlogged packs are filled after the panels to be blasted are prepared.

A typical 8-hour pack filling shift consists of a number of required activities in addition to the actual filling of packs. The actual time available for the filling of packs during a shift is influenced by these additional daily shift activities which can be planned, 'normal shift activities' or unforeseen. These additional activities reduce the time available for pack construction and filling during a shift and consequently influences pack production.

In order to maximise the pack production of the mine, the time allocated to filling of packs should be kept at a maximum by optimising the time spent on other activities.

Planned, 'normal shift activities': Table 1 presents the activities that are identified as 'normal shift activities' for grout pack production crews. The activities listed will vary from mine to mine and the table provides typical items witnessed by the author. 
Table 1. Typical planned, 'normal shift activities' for grout pack production crews.

\begin{tabular}{ll}
\hline Activity & Description \\
\hline Travel & $\begin{array}{l}\text { Start of shift: The time required from entering shaft cage on surface and travel to the } \\
\text { underground safety meeting locations and workplaces. } \\
\text { During shift: The time required to travel between different workplaces where grout } \\
\text { production is required. } \\
\text { End of shift: The time required for travel from the workplace back to shaft cage and } \\
\text { finally up to surface. }\end{array}$ \\
Grouting crews may be required to attend daily safety and planning meetings prior to \\
commencing work.
\end{tabular}

Source: own study

Figure 7 presents a typical timesheet of a pack filling crew during an 8-hour shift. The following should be noted:

- The timesheet assumes that the pack filling operation utilises relay stations for the grout system.

- The table makes provision for one grouting crew to consecutively fill packs in two panels by allowing additional time spent on travel and grouting preparation activities between panels.

- Packs were constructed in the preceding shift and are ready for filling upon arrival of grouting crews.

- The timesheet excludes unforeseen activities which should not form part of a normal pack filling shift.

Based on the timesheet a total of $3 \mathrm{~h} 30 \mathrm{~min}$ was available for pack filling during the 8-hour shift. Historical grout plant audits conducted by $\mathrm{P} \& \mathrm{C}$ suggests that this available time can vary between $1 \mathrm{~h} 30 \mathrm{~min}$ and $4 \mathrm{~h} 00 \mathrm{~min}$.

Unforeseen shift activities: A number of 'unforeseen shift activities' that should not form part of the 'normal shift activities' were identified during historical grout plant audits conducted by $\mathrm{P} \& \mathrm{C}$. These activities further reduce the available time for pack filling and consequently influences pack production. Some of the identified activities cannot be avoided and provision should be made during planning stages to address and mitigate the time spent on the relevant activity. 


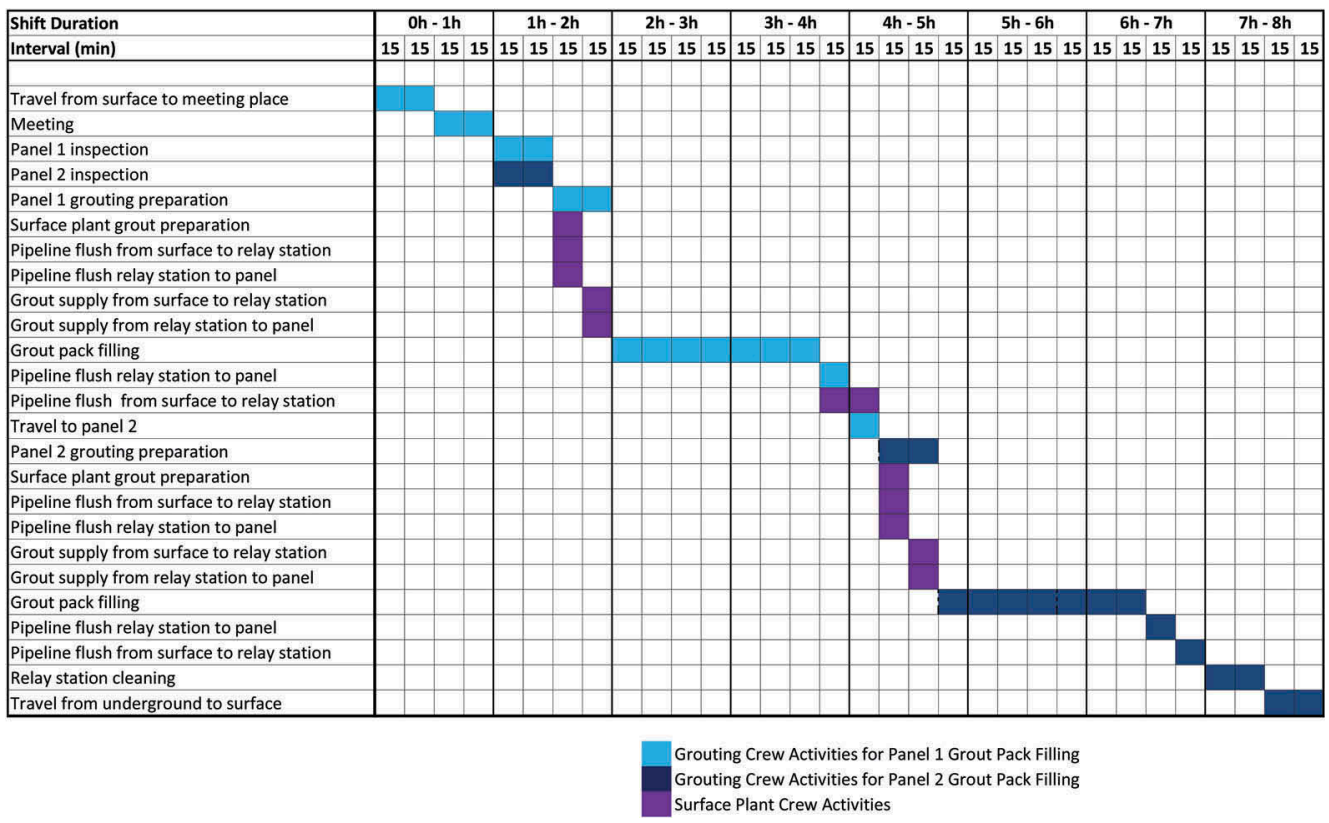

Figure 7. Typical time sheet of pack filling crew over 8 hour shift.

Source: own study

Table 2 presents the 'unforeseen shift activities' that were identified during previous studies.

Previous audits have shown that the time spent on unforeseen activities can significantly reduce the time available for pack filling and even result in a loss of a complete grouting shift. All unforeseen activities should be mitigated during planning stages in order to maximise the pack production of the mining operation.

\subsection{Grout plant utilisation}

\subsubsection{Number of available production days per month ( $\left.N_{\text {PRODUCTION }}\right)$}

The following factors influence the number of available production days:

- Annual shutdown for maintenance

- Work schedule of grouting crews

The average number of available production days per month can be calculated as follows:

$$
N_{\text {PRODUCTION }}=\frac{\left(365-N_{\text {MAINTENANCE }}\right) \times \eta}{12}
$$

where:

$\mathrm{N}_{\text {PRODUCTION }}=$ number of available grout pack production days per month

$\mathrm{N}_{\text {MAINTENANCE }}=$ number of scheduled shut-down days per annum for maintenance, etc.

$\eta=$ availability factor of grout plant and underground staff

Platinum mining operations in South Africa generally work on an 11-days per fortnight schedule. In this case an availability factor of $78.6 \%(11 / 14)$ will be applied. 
Table 2. Typical planned, 'unforeseen shift activities' for grout pack production crews.

Activity
Additional traveling time
Grouting preparations that should not form of
"normal" grouting preparation

Non- or malfunctioning equipment Description

Time spent on traveling in addition to the normal travel activities listed in Table 1.

Operations where packs are prepared by grouting staff require the grout materials (bags, jackpots and wooden poles) to be present upon arrival of the crew. This may not always have been completed during preceding shifts due to a variety of reasons. The fetching of these materials should not form part of the 'normal' grouting shift.

Operations where packs are prepared by mining staff require this activity to be completed in preceding shifts but may not always be completed due to a variety of reasons. These grouting preparations that should not form part of the 'normal' grouting preparations includes transporting of pack support materials, measuring the required length of the wooden pole used to provide initial bag support before filling, mounting of packs, wooden pole and hydraulic jackpod and pressurizing of the jackpod. Non- or malfunctioning equipment used for pack construction and filling requires pack filling crews to repair or replace the item during the shift.

Absence or insufficient number of prepared packs The absence or insufficient number of prepared packs to be pumped upon arrival in a panel require crews spent additional time on travel to another panel where packs may be prepared or even lose an entire shift.

Panel cleaning In order to ensure adequate support of panel hanging wall, panel areas are cleaned of blasted rock and debris prior to the construction of packs. The cleaning of panels is usually done during the preceding blasting shift. If a panel is not cleaned upon the arrival of grouting crews, packs cannot be installed. Uncleaned panels can cause a reduction in time available for filling or even the loss of an entire shift.

Installing temporary supports Panel inspections may require the installation of temporary supports if ground conditions are unsafe.

Grout piping problems

Relay station problems

Additional meetings/discussions Grout piping problems can include blocked pipes, grout pipes bursting, etc.

Relay station problems can include blockages, equipment failures, etc.

Additional time spent on meetings or discussions when required.

Unavoidable mining activities Mining activities occurring in conjunction with the grouting shift can also influence the time available for pack filling. These mining activities includes injuries, mucking of raises and gulleys during grouting shifts and skips receiving material from nearby orepasses are not emptied before grouting shift begins. (Grout pack filling cannot occur if a skip at a nearby orepass is full as this can cause the grout material to run into the skip and setting). 


\subsubsection{Lost production days per month ( $N_{\text {LOST DAYS }}$ )}

A number of factors can cause the available grout pack filling production days per month to be "lost" and consequently decrease the utilisation of the filling operation, namely:

- Labour (staff strikes, staff shortages, etc.)

- Unscheduled maintenance

- Mining stoppages (accidents, etc.)

A direct result of these "lost days" is an increase in the required grout pack production profile for the remaining production days.

\subsubsection{Effective number production days per month $\left(N_{\text {EFFECTIVE }}\right)$}

The effective number of production days available per month is the determined as follows:

$$
N_{\text {EFFECTIVE }}=N_{\text {PRODUCTION }}-N_{\text {LOST DAYS }}
$$

where:

$\mathrm{N}_{\text {EFFECTIVE }}=$ effective number of available grout pack production days per month

$\mathrm{N}_{\text {PRODUCTION }}=$ number of available grout pack production days per month .

$\mathrm{N}_{\text {LOST DAYS }}=$ number of un-scheduled lost days per month

Allowance for a number of lost production days should made during planning stages to ensure that the filling operation will still meet the required production profile of the mine.

\subsection{Required grout plant/s output capacity}

Based on the total volume of grout required as discussed in section 4 , the time available for pack filling during the day- and nightshifts and the effective number of production days available for the month, the required grout plant output flow rate can be calculated as follows:

$$
Q_{R E Q U I R E D}=\frac{V_{G}}{N_{\text {EFFECTIVE }} \times\left(h_{D A Y S H I F T}+h_{N I G H T S H I F T}\right)}
$$

where:

$\mathrm{Q}_{\mathrm{REQUIRED}}=$ required grout flow rate to underground operations $\left(\mathrm{m}^{3} / \mathrm{h}\right)$

$\mathrm{V}_{\mathrm{G}}=$ total volume of grout required for month $\left(\mathrm{m}^{3}\right)$

$\mathrm{N}_{\text {EFFECTIVE }}=$ effective number of available grout pack production days per month

$\mathrm{h}_{\text {DAYSHIFT }}=$ hours available for pack filling during dayshift

$\mathrm{h}_{\text {NIGHTSHIFT }}=$ hours available for pack filling during nightshift

The surface grout plant/s actual output capacity discussed in section 6 should exceed or, as a minimum requirement, match the surface grout plant/s required output capacity ( $Q_{\text {REQUiRED }}$ ) to satisfy the production profile of the mine.

It is crucial that mine staff understands the hours available during a shift for pack filling. Grout plants should be sized to provide the required instantaneous flow rate to the underground operations. Increases in mining production will increase the required grout plant/s output capacity and sufficient provision should be made during planning stages to address planned future increases in the production profile pf the mine.

\section{ACTUAL GROUT PLANT/S PRODUCTION CAPACITY}

Grout plants utilized in the South African mines generally consist of a batch mixing system with a continuous feed to underground operations. Tailings, fly ash, cement and 
water is blended in a mixing tank to produce a grout material at a design mixture density. This grout material is then fed to a range of feed pumps which deliver the material to underground operations via a number of grout ranges.

The maximum grout output flow rate that can be delivered from surface to underground is determined by the lowest capacity of the following:

- Plant mixing system

- Grout plant pumps

- Surface grout piping

- Shaft grout piping

The surface grout plant/s actual output capacity is determined by the plant mixing system.

\subsection{Plant mixing system output flow rate}

The capacities of the surface grout plants' individual batch mixing systems determine the maximum volume of grout that can be produced per hour. Each grout blend component is fed consecutively into the mixing tank at a specific mass flow rate, after which the blend is mixed and transferred to grout storage tanks. The total mass flow rate of the various grout blend components in conjunction with the blend mixing and transfer time determine the continuous output flow rate of the mixing system.

$$
Q_{A V A I L A B L E}=\left(\frac{m_{t}}{\rho_{t}}+\frac{m_{f}}{\rho_{f}}+\frac{m_{c}}{\rho_{c}}+\frac{m_{w}}{\rho_{w}}\right) \times \frac{3600}{\left(t_{t}+t_{f}+t_{c}+t_{w}+t_{m}\right)}
$$

where:

$\mathrm{Q}_{\text {AVAILABLE }}=$ available grout flow rate to underground operations $\left(\mathrm{m}^{3} / \mathrm{h}\right)$

$\mathrm{m}=$ mass added to mixing tank per batch $(\mathrm{kg} / \mathrm{batch})$

$\rho=$ density of each component into the mixing tank $\left(\mathrm{kg} / \mathrm{m}^{3}\right)$

$\mathrm{t}=$ feed time of each component into the mixing tank ( $/$ /batch)

$\mathrm{t}_{\mathrm{m}}=$ the time dedicated to mixing the components and transferring the blend into the grout pumps feed tank (s/batch)

Subscripts:

$\mathrm{t}=$ tailings

$\mathrm{f}=$ usually fly ash, but can be any supplementary cementitious material

$\mathrm{c}=$ cement

$\mathrm{w}=$ water

\subsection{Grout plant pumps capacities}

The combined grout pump capacities should be sufficient to deliver the total mixing system output flow rate to underground operations at the required pumping pressure.

Standby pumps are advised to ensure $100 \%$ pumping capacity during maintenance or pump failures.

\subsection{Piping ranges}

The quantity of grout piping ranges from the plant to the underground operations should be sufficient to ensure that $100 \%$ of the full mixing system output flow rate can always be delivered to underground operations.

Standby pipe ranges are advised to ensure $100 \%$ grout delivery capacity during pipe maintenance, failures or blockages. 


\section{REQUIRED VS ACTUAL GROUT PLANT/S PRODUCTION CAPACITY}

After the surface grout plant/s required output capacity (QREQUIRED) calculated, it should be compared with the surface grout plant/s actual output capacity (Q to ensure that the plant/s will be able to satisfy the required production profile of the mining operation.

If the required output capacity exceeds the actual output capacity of the surface grout plant/s, the actual grout pack production will not be able to satisfy the required production profile. The actual output capacity of the surface grout plant/s can be increased as discussed in the following sections.

\subsection{Increase the shift hours dedicated to pack filling}

The number of shift hours dedicated to the actual filling of packs can be increased by mitigating the time spend on unforeseen activities as well as by optimising the time spend on 'normal' shift activities. 'Normal' shift activities which can be streamlined should be identified and procedures be adopted to reduce unnecessary time spend on these activities.

\subsection{Mitigate the number of lost production days for month}

By decreasing the number of 'lost' production days per month, the surface grout plants required output capacity will decrease. 'Lost' days as a result of labour difficulties and mining stoppages are however generally difficult to predict and control. Unscheduled maintenance can be mitigated by ensuring that regular inspections and preventative maintenance is conducted on grout equipment and piping to identify possible failures in the near future.

\subsection{Overtime production}

Overtime production will increase the effective number of production days available and hence decrease the surface grout plant/s required output capacity. Overtime production however increases labour costs and should be seen as a temporary solution.

\subsection{Utilise other existing grout plants to supply grout to the operation}

If other grout plants exist in the vicinity of the mine operation they may be utilised as an additional supply to the operation. The utilisation of additional existing grout plants will require the installation or rerouting of additional grout piping. If the grouting operation utilises underground relay stations to distribute grout to panels, the relay stations may also require additional capacity to manage the increase in grout supply from the surface.

\subsection{Construction of additional grout plants to supply grout to the operation}

The construction of additional grout plants to supply grout to the mining operation will require capital investment as well as the employment of additional operations staff. Again, if the grouting operation utilises underground relay stations to distribute grout to panels, the relay stations may also require additional capacity to manage the increase in grout supply from the surface.

\section{GROUT PLANT AND RETICULATION SYSTEM AUDITS}

If a mining operation is experiencing difficulties relating to the grout production, it is advised that a grout plant and reticulation system audit is completed. Audits should include establishing the current grout cycle, establishing current grout reticulation to determine maximum 
possible grout plant throughput. The audit should then determine the required grout production profile of the mine for current and future operations.

Based on the information gathered during the audit as well as historical data analysis, possible areas of concerns can be identified. These areas are then analysed in order to make suitable recommendations to rectify the problems experienced.

\section{CONCLUSION}

To determine the required monthly grout volumes of a mining operation a variety of parameters needs to be considered. These parameters should be accurately estimated at the start of a production month and are based inter alia on historical data and the mining plan of the operation.

Grout plants should be sized to provide the required flow rate to the underground operations for the hours available during a shift for pack filling. The actual grout plant/s production capacity of a mining operation should exceed the required grout plant/s production capacity to satisfy mining requirements. The actual output capacity of the surface grout plant/s can be increased by optimisation of the existing system as discussed in this paper.

If a mining operation is experiencing difficulties relating to the grout production it is advised that a grout plant and reticulation system audit is completed to determine the mine requirements as well as the parameters influencing the grout pack production profile of the mine.

\section{BIBLIOGRAPHY}

Daehnke, A, van Zyl, M and Roberts, M.K.C. 2017. Review and application of stope support design criteria. Journal of The South African Institute of Mining and Metallurgy, vol. 101, no 3, pp. 135-164. 